Supporting Information for

Anion Recognition by a Silanediol-based Receptor

Shin-ichi Kondo, * Tomomi Harada, Ryoji Tanaka, and Masafumi Unno*

Department of Chemistry, Faculty of Engineering, Gunma University, Kiryu, Gunma 376-8515, Japan

E-mail: kondo@chem.gunma-u.ac.jp

General. All reagents used were of analytical grade. Acetonitrile was dried and distilled over calcium hydride. Tetrahydrofuran was dried over Na/benzophenone. UV-vis spectra were recorded on a Shimadzu UV-2500PC spectrometer with thermal regulator $\left( \pm 0.5{ }^{\circ} \mathrm{C}\right) .{ }^{1} \mathrm{H}$ NMR spectra were measured on a JEOL AL300 (300 MHz) spectrometer and referenced to tetramethysilane as an internal standard. Electrospray ionization mass spectra (ESI-MS) were recorded on an Applied Biosystems/MDS-Sciex API-100 spectrometer. Fluorescence spectra were recorded on a Hitachi F-4500 fluorescence spectrometer. Melting points were determined with a Yanagimoto micro melting point apparatus and are uncorrected.

\title{
X-ray crystallographic study of $\mathbf{1} \cdot \mathbf{C l}$.
}

A colorless prismatic crystal of $\mathrm{SiC}_{38} \mathrm{Cl}_{7} \mathrm{O}_{2} \mathrm{NH}_{54}$ having approximate dimensions of $0.30 \times 0.30 \times$ $0.20 \mathrm{~mm}$ was mounted in a loop. All measurements were made on a Rigaku RAXIS-IV Imaging Plate diffractometer with graphite monochromated $\mathrm{Mo}-\mathrm{K} \alpha$ radiation. Data were collected and processed using the CrystalClear program (Rigaku). The structure was solved by direct methods using the SIR92 program $^{1}$ and expanded using Fourier techniques using DIRDIF94 program. ${ }^{2}$ The hydrogen atoms on the silicon atoms and chloroform molecules could be found in the difference Fourier map and refined with isotropic displacement coefficients, respectively. The other hydrogen atoms were calculated in ideal positions and refined isotropically.

\section{${ }^{1}$ H NMR titrations}

A solution of $1\left(5.0 \times 10^{-3} \mathrm{~mol} \mathrm{dm}^{-3}\right)$ in $\mathrm{CDCl}_{3}$ was prepared in an NMR tube. Aliquots of a stock solution of anions (tetrabutylammonium salts) dissolved in a solution of $1\left(5.0 \times 10^{-3} \mathrm{~mol} \mathrm{dm}^{-3}\right)$ in $\mathrm{CDCl}_{3}$ were added and the spectrum were recorded, repeatedly. Each measurement was at least duplicated. The association constants were calculated from the chemical shifts of naphthyl CHs (all cases) and silanol $\mathrm{OH}$ (except for $\mathrm{AcO}^{-}$) by a self-written nonlinear least-square-fitting program. 


\section{UV-vis and fluorescence titrations}

A solution of $1\left(6.67 \times 10^{-5}\right.$ for $\mathrm{UV}$-vis and $3.33 \times 10^{-5} \mathrm{~mol} \mathrm{dm}^{-3}$ for fluorescence spectroscopy) in $\mathrm{CHCl}_{3}$ was titrated with incremental amounts of appropriate anion $\left(0.01 \mathrm{~mol} \mathrm{dm}^{-3}\right)$ in $\mathrm{CHCl}_{3}$. The UV-vis titration data was fitted to a 1:1 binding isotherm between $250-330 \mathrm{~nm}$ by a self-written nonlinear least-square-fitting program.

\section{References}

1. Altomare, A.; Burla, M. C.; Camalli, M.; Cascarano, M.; Giacovazzo, C.; Guagliardi, A.; Polidori, G. J. Appl. Cryst. 1994, 27, 435.

2. Beurskens, P. T.; Admiraal, G.; Beurskens, G.; Bosman, W. P.; de Gelder, R.; Israel, R.; Smits, J. M. M. The DIRDIF-94 program system, Technical Report of the Crystallography Laboratory, University of Nijmegen, The Netherlands. 

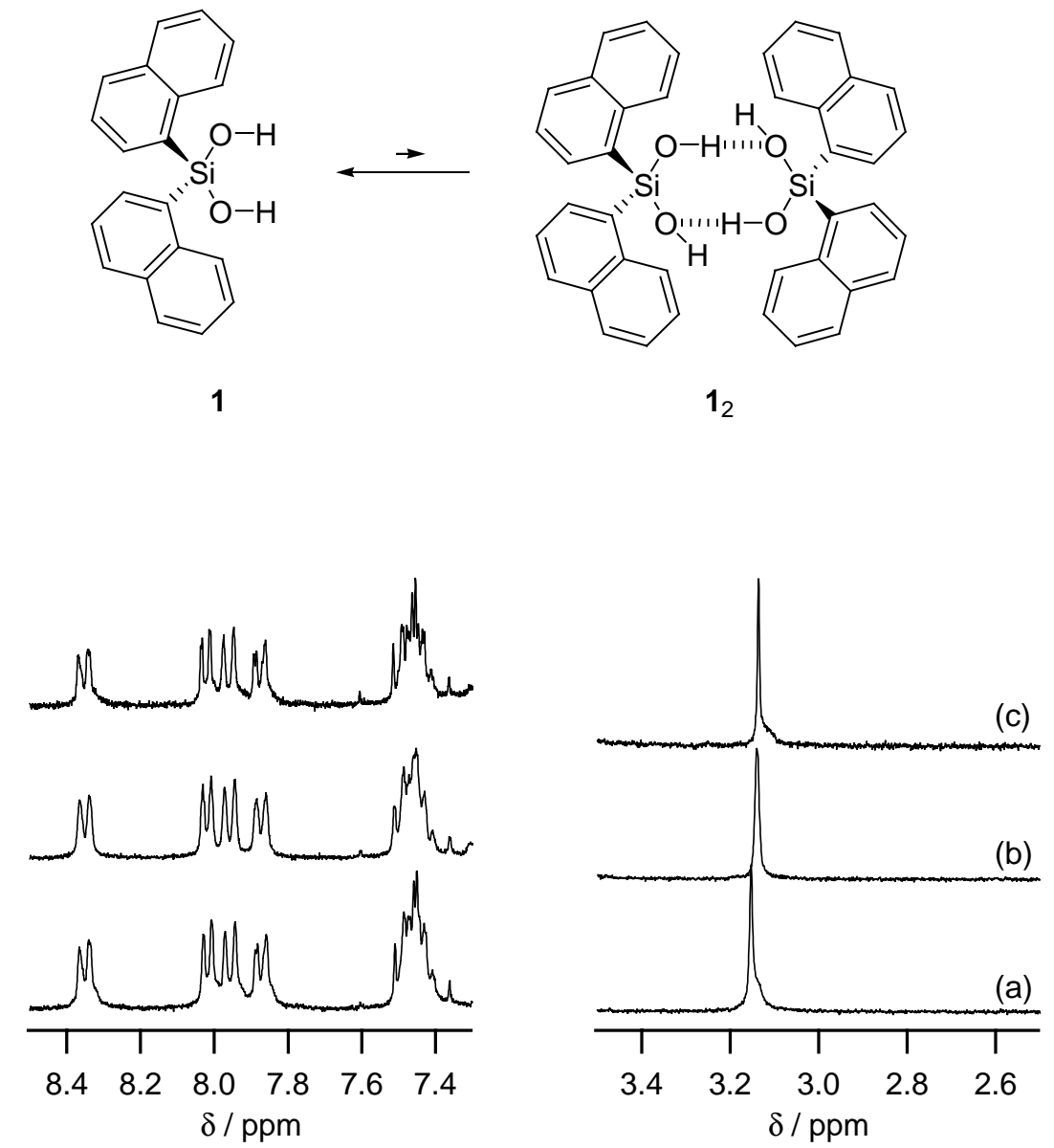

Figure S1. Dilution experiment of $\mathbf{1}$ in $\mathrm{CDCl}_{3}$ by ${ }^{1} \mathrm{H}$ NMR. $[\mathbf{1}]=5.0 \times 10^{-3}$ (a), $2.5 \times 10^{-3}$ (b), and 1.25 $\times 10^{-3}$ (c) $\mathrm{mol} \mathrm{dm}^{-3}$. 

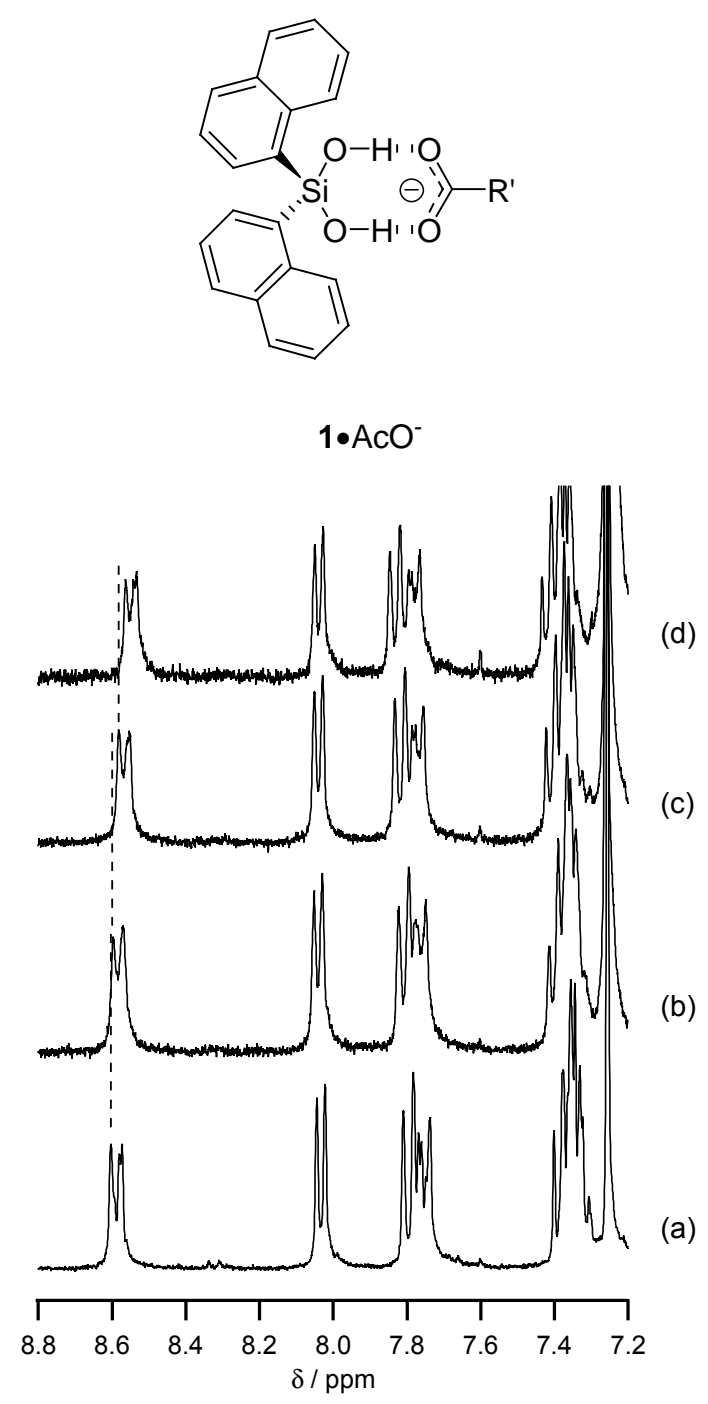

Figure S2. Dilution experiment by ${ }^{1} \mathrm{H}$ NMR of $\mathbf{1}$ in the presence of 1 equiv. of tetrabutylammonium acetate in $\mathrm{CDCl}_{3} \cdot[\mathbf{1}]=\left[\mathrm{AcO}^{-}\right]=5.0 \times 10^{-3}(\mathrm{a}), 2.5 \times 10^{-3}(\mathrm{~b}), 1.25 \times 10^{-3}(\mathrm{c})$, and $6.25 \times 10^{-4}$ (d) mol $\mathrm{dm}^{-3}$. 


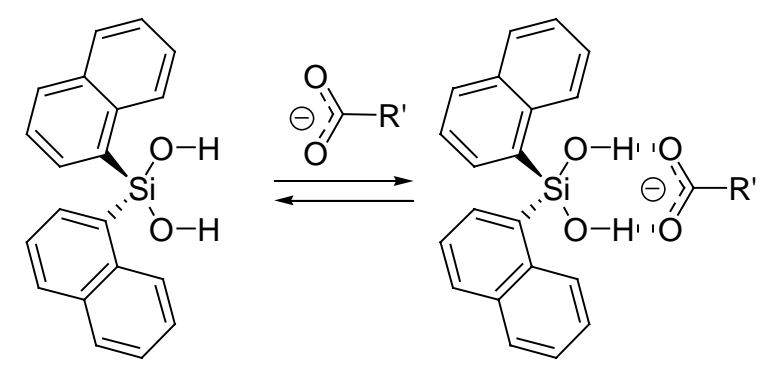

1

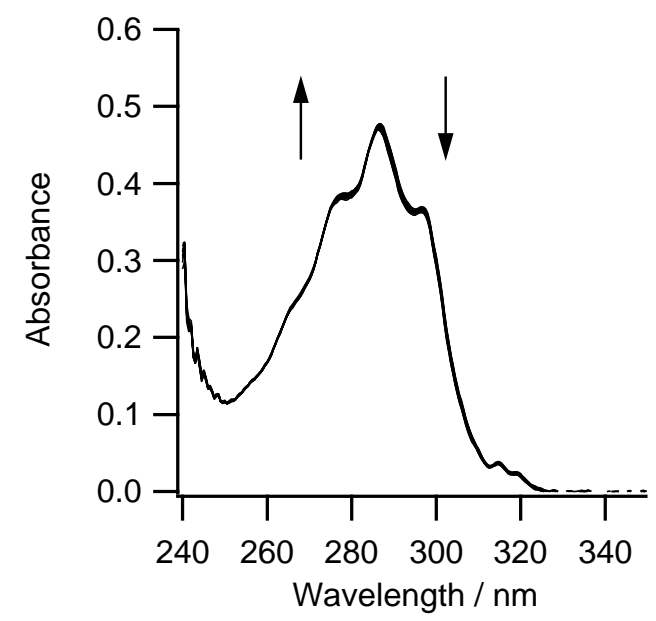

Figure S3. UV-vis spectroscopic titrations of $\mathbf{1}$ in $\mathrm{CHCl}_{3}$. [1] $=3.33 \times 10^{-5} \mathrm{~mol} \mathrm{dm}^{-3}$. [AcO $]=0-1.33$ $\times 10^{-4} \mathrm{~mol} \mathrm{dm}^{-3}$. 



1



Figure S4. UV-vis spectroscopic titrations of $\mathbf{1}$ in $\mathrm{CHCl}_{3}$. $[\mathbf{1}]=1.67 \times 10^{-5} \mathrm{~mol} \mathrm{dm}{ }^{-3}, \lambda_{\mathrm{ex}}=270 \mathrm{~nm}$. $\left[\mathrm{AcO}^{-}\right]=0-6.67 \times 10^{-5} \mathrm{~mol} \mathrm{dm}^{-3}$. 